\title{
Soft Mango Firmness Assessment Based on Rayleigh Waves Generated by a Laser-Induced Plasma Shock Wave Technique
}

\author{
Nayuta Arai ${ }^{1}$, Masafumi Miyake ${ }^{1}$, Kengo Yamamoto ${ }^{1}$, Itsuro Kajiwara ${ }^{2}$ (D) and Naoki Hosoya ${ }^{3, *}$ \\ 1 Division of Mechanical Engineering, Shibaura Institute of Technology, 3-7-5 Toyosu, Koto-ku, \\ Tokyo 135-8548, Japan; md19004@shibaura-it.ac.jp (N.A.); md19074@shibaura-it.ac.jp (M.M.); \\ md16095@shibaura-it.ac.jp (K.Y.) \\ 2 Division of Human Mechanical Systems and Design, Hokkaido University, N13, W8, Kita-ku, Sapporo-shi, \\ Hokkaido 060-8628, Japan; ikajiwara@eng.hokudai.ac.jp \\ 3 Department of Engineering Science and Mechanics, Shibaura Institute of Technology, 3-7-5 Toyosu, Koto-ku, \\ Tokyo 135-8548, Japan \\ * Correspondence: hosoya@sic.shibaura-it.ac.jp; Tel.: +81-3-5859-8055
}

Citation: Arai, N.; Miyake, M. Yamamoto, K.; Kajiwara, I.; Hosoya, N. Soft Mango Firmness Assessment Based on Rayleigh Waves Generated by a Laser-Induced Plasma Shock Wave Technique. Foods 2021, 10, 323. https://doi.org/10.3390/foods10020323

Academic Editors: Mladen Brnčić and Urszula Tylewicz

Received: 17 December 2020

Accepted: 29 January 2021

Published: 3 February 2021

Publisher's Note: MDPI stays neutral with regard to jurisdictional claims in published maps and institutional affiliations.

Copyright: (c) 2021 by the authors. Licensee MDPI, Basel, Switzerland This article is an open access article distributed under the terms and conditions of the Creative Commons Attribution (CC BY) license (https:// creativecommons.org/licenses/by/ $4.0 /)$.

\begin{abstract}
Many methods based on acoustic vibration characteristics have been studied to indirectly assess fruit ripeness via fruit firmness. Among these, the frequency of the ${ }_{0} \mathrm{~S}_{2}$ vibration mode measured on the equator has been examined, but soft-flesh fruit do not show the ${ }_{0} \mathrm{~S}_{2}$ vibration mode. In this study, a Rayleigh wave is generated on a soft mango fruit using the impulse excitation force generated by a laser-induced plasma shock wave technique. Then, the flesh firmness of mangoes is assessed in a non-contact and non-destructive manner by observing the Rayleigh wave propagation velocity because it is correlated with the firmness (shear elasticity), density, and Poisson's ratio of an object. If the changes in the density and Poisson's ratio are small enough to be ignored during storage, then the Rayleigh wave propagation velocity is strongly correlated to fruit firmness. Here, we measure the Rayleigh wave propagation velocity and investigate the effect of storage time. Specifically, we investigate the changes in firmness caused by ripening. The Rayleigh wave propagation velocity on the equator of Kent mangoes tended to decrease by over $4 \%$ in $96 \mathrm{~h}$. The Rayleigh wave measured on two different lines propagated independent distance and showed a different change rate of propagation velocity during $96-\mathrm{h}$ storage. Furthermore, we consider the reliability of our method by investigating the interaction of a mango seed on the Rayleigh wave propagation velocity.
\end{abstract}

Keywords: firmness; laser-induced plasma; mango; non-contact non-destructive excitation; Rayleigh wave propagation velocity; shock wave

\section{Introduction}

People who work in agriculture assess fruit ripeness based on a variety of indexes such as size, color, shape, and aroma prior to harvest. Moreover, the soluble solid content, acidity, and firmness, which are related to fruit ripeness, are often used as ripeness indexes [1-9]. These indexes are classified using optical, biochemical, or mechanical methods.

Many approaches based on an optical method have been proposed to assess the soluble solid content or acidity of the fruit by irradiating with visible or near-infrared light $[2,3,6,7,9-15]$. Although these methods have practical applications, they are difficult to apply to fruit whose peel does not change color or does not transmit light during the ripening stage.

Biochemical methods detect aromatic volatiles and assess ripeness by gas chromatography or an electric nose [16-21]. This approach is not suitable to assess the ripeness of fruit that emits a weak odor. In addition, neither optical nor biochemical methods can assess the ripeness of fruit such as avocado, which show low soluble solid content or acidity. 
Consequently, many mechanical methods to assess the firmness of fruit as a ripeness index have been proposed [22-31].

In mechanical methods, dynamic characteristics such as the natural frequencies or vibration modes are assessed by contact devices such as an impact hammer, pendulum, or vibrator because the natural frequency, which is called the ${ }_{0} S_{2}$ mode, is strongly correlated to fruit firmness [32]. However, traditional contact devices are not suitable to excite soft fruit because the excitation damages the fruit flesh. Furthermore, it is assumed that the strong viscoelastic feature of soft fruit limits excitation of the ${ }_{0} \mathrm{~S}_{2}$ mode frequency.

Previously, we demonstrated a non-contact and non-destructive firmness assessment system by applying a shock wave generated by laser-induced plasma (LIP) as an impulse excitation force [33]. The changes to the firmness of apples during storage were assessed by monitoring the shift in the ${ }_{0} S_{2}$ mode frequency. As the firmness decreases, the ${ }_{0} S_{2}$ mode frequency shifts to a lower frequency band. In our LIP shock wave excitation technique, a plasma is formed by condensing a laser beam from a high-output neodymium: yttrium aluminum garnet (Nd:YAG) pulsed laser to a point near the excitation point. A shock wave is generated when the plasma expands at an ultrasonic speed. This shock wave is applied to a test piece as an impulse excitation force. The LIP shock wave excitation technique has been widely developed for assessments or non-destructive inspections of the dynamic characteristics of mechanical structures as well as for the generation of a point sound source [34-37].

Laser ablation (LA) can generate a larger excitation force than a LIP shock wave. In LA, a plasma plume with a high temperature and high density is formed by directly irradiating a high-output pulsed laser to the excitation point of a target object (solid surface). When mass $\Delta m$ is emitted from the object at velocity $v$, the momentum, which is given by $\Delta m v$, acts as the impulse to the object. Many studies have applied LA to vibration or acoustic tests for mechanical structure assessments [38,39], bolt loosening detection [40], infrastructure inspection [41], damage detection [42], and mechanical property measurement in hydrogels [43]. Because LA causes sub-millimeter-sized damage on the object's surface, it is difficult to assess its firmness via LA and maintain commercial value.

One firmness assessment for apples uses thermoelastic wave propagation on the apple surface by a laser ultrasonic (LU) technique [44]. LU uses a lower laser fluence (laser pulse energy) than LA. LU and LA both irradiate a laser beam to a target structure directly. LU is often used to inspect mechanical structures or composite materials $[45,46]$ because it can produce a non-contact and non-destructive excitation force. However, LU has three main drawbacks. It produces a measured elastic wave with a small amplitude. It has a low signal-to-noise ratio, and it requires numerous measurements. Additionally, it can also generate LA, depending on the material of the target object, wavelength of the pulsed laser, and laser fluence. The threshold to generate LU or LA is difficult to determine, which limits the practicality of this method to assess fruit firmness.

In this paper, a Rayleigh wave is generated on the surface of a soft fruit peel using an impulse excitation force generated by a LIP shock wave technique. The flesh firmness of soft fruit is assessed in a non-contact and non-destructive manner by observing the Rayleigh wave propagation velocity. A Rayleigh wave is a type of surface elastic wave that propagates on a target object and is commonly used for the non-destructive assessment of Young's modulus [47] or defect inspection [48-50]. In addition, Rayleigh wave propagation on soft gels and flesh fruit has been investigated [51,52]. The Rayleigh wave velocity is correlated to the shear elasticity (firmness) of an object, density, and Poisson's ratio. If the changes in the density and Poisson's ratio of the fruit can be ignored during the storage period, only shear elasticity (firmness) changes. According to a previous study [52], shear elasticity is correlated to fruit flesh firmness. We can infer that the Rayleigh wave propagation velocity decreases as shear elasticity decreases. The LIP shock wave excitation technique can improve the signal-to-noise ratio because it produces a larger excitation force compared to LU. An assessment of the firmness of soft fruit by generating a Rayleigh wave via a LIP shock wave excitation technique has yet to be reported. 
Herein, we report such an assessment using mangoes as a soft fruit. First, we demonstrate that a Rayleigh wave is generated on a mango fruit by applying a LIP shock wave as an impulse excitation force. We obtain the vibration responses on each measurement point by a laser Doppler vibrometer (LDV). Then, the propagation velocity is calculated from those time responses. Second, the change in the Rayleigh wave propagation velocity is regarded as the change in firmness during storage. We assess the firmness of a mango fruit by monitoring the decreased Rayleigh wave velocity. Finally, we examine the location of the mango fruit where the Rayleigh wave should be generated to assess firmness to avoid possible bias from the large mango seed.

\section{Materials and Methods}

\subsection{LIP Shock Wave Excitation Technique}

LIP is a phenomenon where plasma with a high temperature and high density is formed by condensing a high-output pulsed laser in air with a laser fluence exceeding $10^{15}\left(\mathrm{~W} / \mathrm{m}^{2}\right)$. As the plasma expands to the surroundings at ultrasonic speed, a shock wave is generated. This shock wave acts on the fruit as an impulse excitation force [53].

Figure 1 shows the firmness assessment system for mangoes based on the LIP shock wave excitation technique. A laser beam from a Nd:YAG pulsed laser (Surelite III-10, Continuum Inc., Milpitas, CA, USA, wavelength $1064 \mathrm{~nm}$, laser beam radius: $4.75 \mathrm{~mm}$, pulse width: $5 \mathrm{~ns}$, maximum output: $850 \mathrm{~mJ}$, and radial divergence angle: $0.25 \mathrm{mrad}$ ) installed on an optical bench was condensed with a plano-convex lens (SLB-20-100P, SIGMAKOKI Co., LTD., Sumida-Ku, Tokyo, Japan, focal length: $100 \mathrm{~mm}$ ) to generate a LIP shock wave near the excitation point on mangoes. The pressure $P^{\mathrm{sh}}(d)(\mathrm{Pa})$ generated by a LIP shock wave is given by [54]:

$$
P^{\mathrm{sh}}(d)=\left(\frac{2}{5}\right)^{2} \frac{2 \zeta_{0}^{5}}{\gamma+1} E d^{-3}
$$

where $d(\mathrm{~m})$ is a distance from the LIP generation point, $\zeta_{0}$ is a constant $\left(\zeta_{0}=0.93\right), \gamma$ is the specific heat ratio $(\gamma=1.41)$, and $E(J)$ is the laser pulsed energy. In this experiment, the pressure $P^{\text {sh }}(d)$ generated by the LIP shock wave is estimated as $2.9 \mathrm{MPa}$ because we set the distance $d$ (hereinafter referred to as the standoff distance) between the excitation point on the mango peel and the LIP generation point to $3 \mathrm{~mm}$.

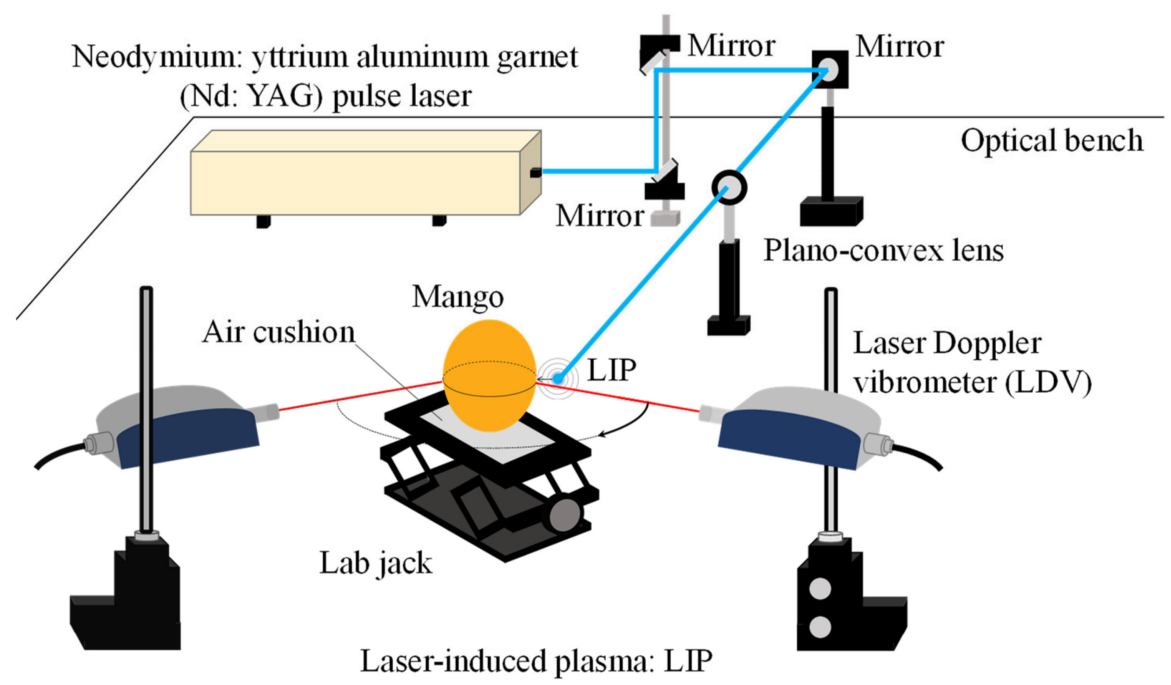

Figure 1. Firmness assessment system for mangoes using a LIP shock wave as a non-contact and non-destructive excitation method.

The vibration responses on a mango are measured by LDV (NLV-2500-5, Polytec $\mathrm{GmbH}$, Waldbronn, Baden-Württemberg, Germany) in a non-contact manner and recorded 
by a spectrum analyzer (A/D: NI PXI-4462, National Instruments Co., Austin, TX, USA, Software: CAT-System, CATEC Inc. Taito-Ku, Tokyo, Japan). In the experiment, we placed reflection seals (approximately $3 \mathrm{~mm} \times 3 \mathrm{~mm}$ ) at each measurement point. We set the sampling frequency, the number of sampling points, and the number of trials to $204.8 \mathrm{kHz}$, 32,768 points, and 5, respectively. The mango was seated on an air cushion to ensure free support.

\subsection{Storage Time and Measurement Paths of Mangoes}

The experiment used 20 Kent mangoes as test material (Table 1). The average mass, density, and circumference (Line A, see Figure 2) were $0.457 \mathrm{~kg}, 1094 \mathrm{~kg} / \mathrm{m}^{3}$, and $27 \mathrm{~cm}$, respectively. Table 2 shows the storage time and measurement paths of the mangoes.

Table 1. Mass, density, and circumference of mangoes.

\begin{tabular}{cccc}
\hline Sample No. & Mass $(\mathbf{g})$ & Density $\left(\mathbf{k g} / \mathbf{m}^{\mathbf{3}}\right)$ & Circumference $(\mathbf{m})$ \\
\hline Average & 457.0 & 1094 & 0.270 \\
1 & 531.9 & 978.0 & 0.240 \\
2 & 510.2 & 1001 & 0.300 \\
3 & 493.9 & 1026 & 0.280 \\
4 & 495.4 & 1064 & 0.298 \\
5 & 493.1 & 990.0 & 0.300 \\
6 & 496.7 & 1158 & 0.284 \\
7 & 490.0 & 1174 & 0.284 \\
8 & 501.8 & 741.0 & 0.277 \\
9 & 437.6 & 1020 & 0.281 \\
10 & 435.9 & 815.0 & 0.280 \\
11 & 371.8 & 1039 & 0.253 \\
12 & 371.7 & 1039 & 0.242 \\
13 & 391.4 & 1094 & 0.262 \\
14 & 401.2 & 1121 & 0.250 \\
15 & 426.5 & 1192 & 0.240 \\
16 & 438.9 & 1227 & 0.280 \\
17 & 465.1 & 1300 & 0.300 \\
18 & 398.3 & 1113 & 0.284 \\
19 & 480.6 & 1343 & 0.281 \\
20 & 519.6 & 1452 & 0.280 \\
\hline & & &
\end{tabular}

Table 2. Measurement paths and storage times of mangoes.

\begin{tabular}{ccc}
\hline Sample No. & Measurement Path & Storage Time (h) \\
\hline $1-5,7,8$ & Line A & $0,48,96$ \\
6 & Line A & $0,24,48,72,96,168,192,216$ \\
$9-20$ & Lines A and B & $0,48,96$ \\
\hline
\end{tabular}

First, we considered the storage time and storage method. Mangoes 1-5 and 9-20 were used to observe the changes in the Rayleigh wave propagation velocity excited on the mango surface at 0,48 , and 96 h of storage. Mango 6 was used to observe the changes in the Rayleigh wave propagation velocity over $216 \mathrm{~h}$ of storage measured in $24 \mathrm{~h}$ increments. Here, " $0 \mathrm{~h}$ " represents the starting time of the experiment for each mango. During the experiments, mangoes were stored at a constant temperature of $19{ }^{\circ} \mathrm{C}$.

Next, we considered the measurement points on mangoes. Figure 2 depicts the measurement points on a mango fruit. Line A was on the equator of the mango, while Line B was orthogonal to the equator. We measured a Rayleigh wave on the equator because a fruit firmness was assessed by vibration tests to obtain the ${ }_{0} S_{2}$ frequency [33]. We also determined Line B, which is orthogonal to the equator. In a previous study where the flesh firmness of watermelon was assessed by measuring the Rayleigh wave propagation velocity [52], the flesh thickness was shown to be correlated to the Rayleigh 
wave propagation velocity. The fruit flesh thickness is small on Line B because mangoes contain large seeds.

Mangoes 1-20 were assessed on Line A, and mangoes 9-20 were assessed on Line B also. Line A consisted of 24 points set in the equatorial direction on the semi-equator in $7.5^{\circ}$ intervals (Figure 2). Line B consisted of 24 points in the orthogonal direction to the equator in $7.5^{\circ}$ intervals, where point 0 is in the opposite direction of the stem end. For both Lines $\mathrm{A}$ and $\mathrm{B}$, we set point 0 as the excitation point and points $1-24$ as the measurement points. Laser beam from LDV was installed in the normal direction to the tangent plane containing each measurement point.

(a) Overview
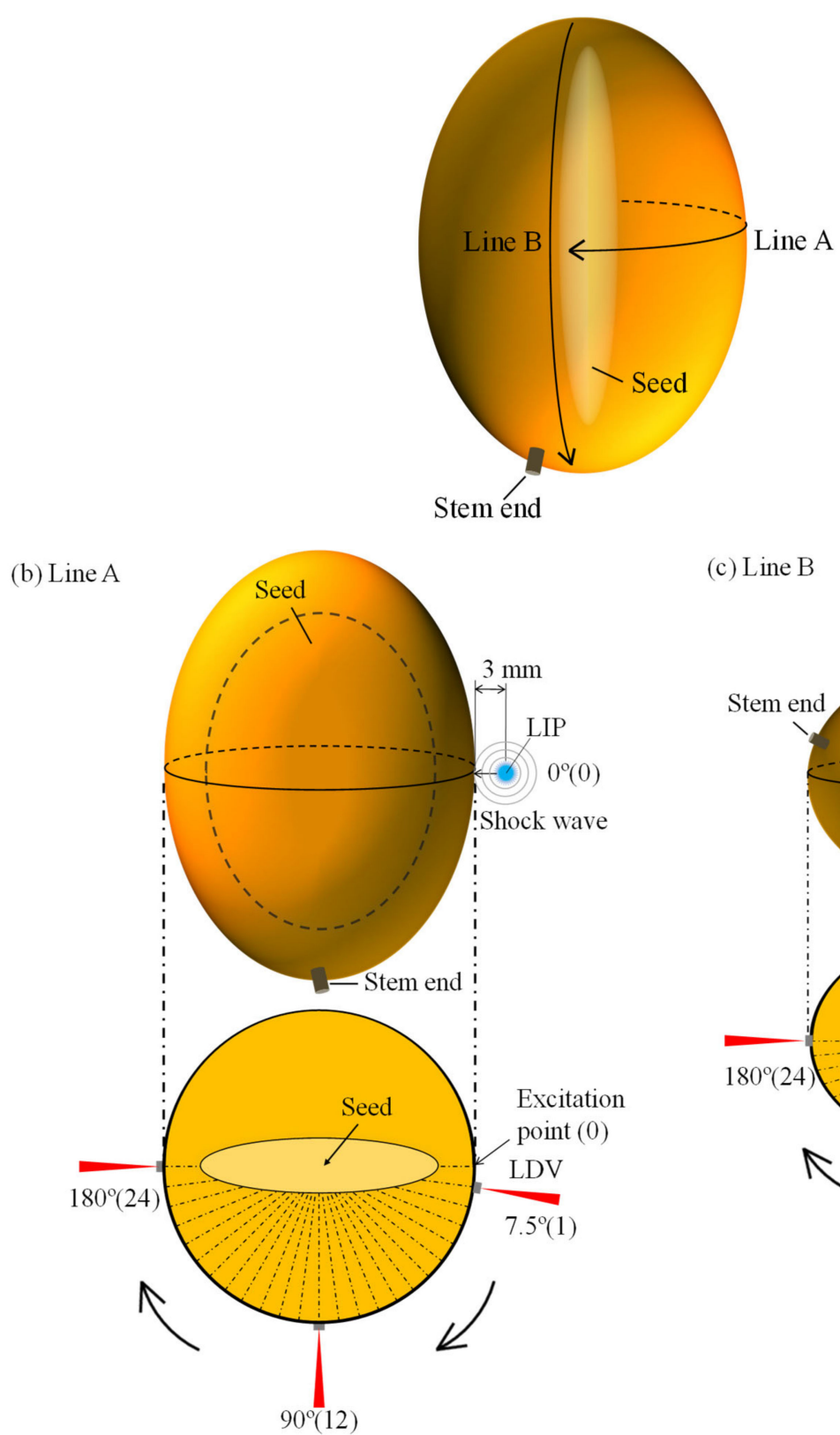

(c) Line B

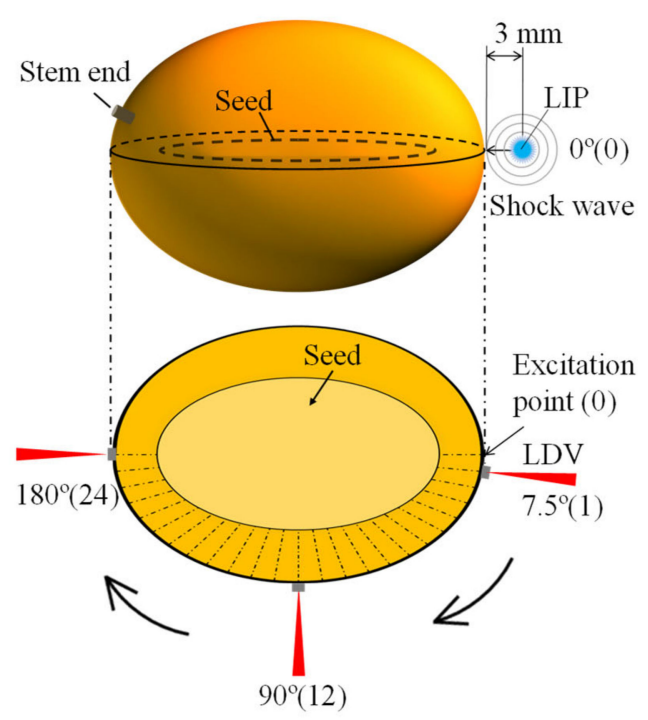

Figure 2. Measurement paths of the Rayleigh wave on a mango. (a) Overview of a mango. (b) Line A represents the measurement points on the equator. (c) Line B represents the measurement points orthogonal to the equator. 


\section{Results and Discussion}

\subsection{Measured Time History Responses and Their Power Spectra}

Figure 3 shows the time history responses and the power spectra of the displacement on mango 6 measured by our system. We compared points $1,12\left(90^{\circ}\right.$ away from point 0$)$, and $24\left(180^{\circ}\right.$ from point 0$)$. The Rayleigh wave was excited with an approximately $10 \mu \mathrm{m}$ amplitude (Figure 3a). The amplitudes of the measured Rayleigh wave at points 12 and 24 were approximately one-tenth of the amplitude of the measured Rayleigh wave at point 1 (Figure $3 \mathrm{~b}, \mathrm{c})$. In addition, the mangoes used in this experiment showed a strong viscoelastic feature because they were damped a few milliseconds after the excitation. The power spectra showed a $12.5 \mathrm{~Hz}$ peak frequency at points 12 and 24 . This frequency was the socalled "rigid body mode", where the mango vibrated without showing elastic deformation because it was seated on an air cushion. Additionally, the $50 \mathrm{~Hz}$ peak frequency appeared at points 1, 12, and 24 due to the power supply noise. For the above reasons, our system can generate a Rayleigh wave on a mango in a non-contact and non-destructive manner. On the other hand, the ${ }_{0} \mathrm{~S}_{2}$ mode frequency, which has traditionally been used as a flesh firmness index for fruit, was not excited on the mangoes used in this experiment.
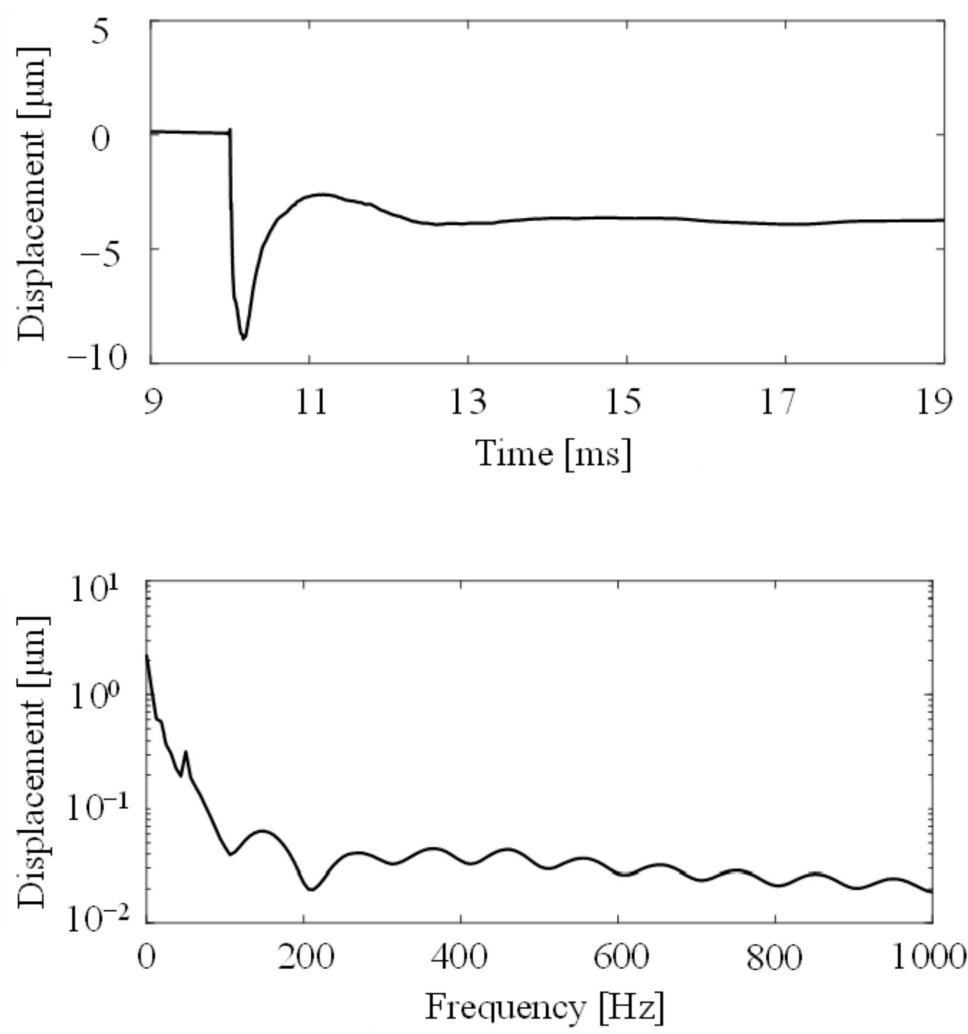

(a)

Figure 3. Cont. 

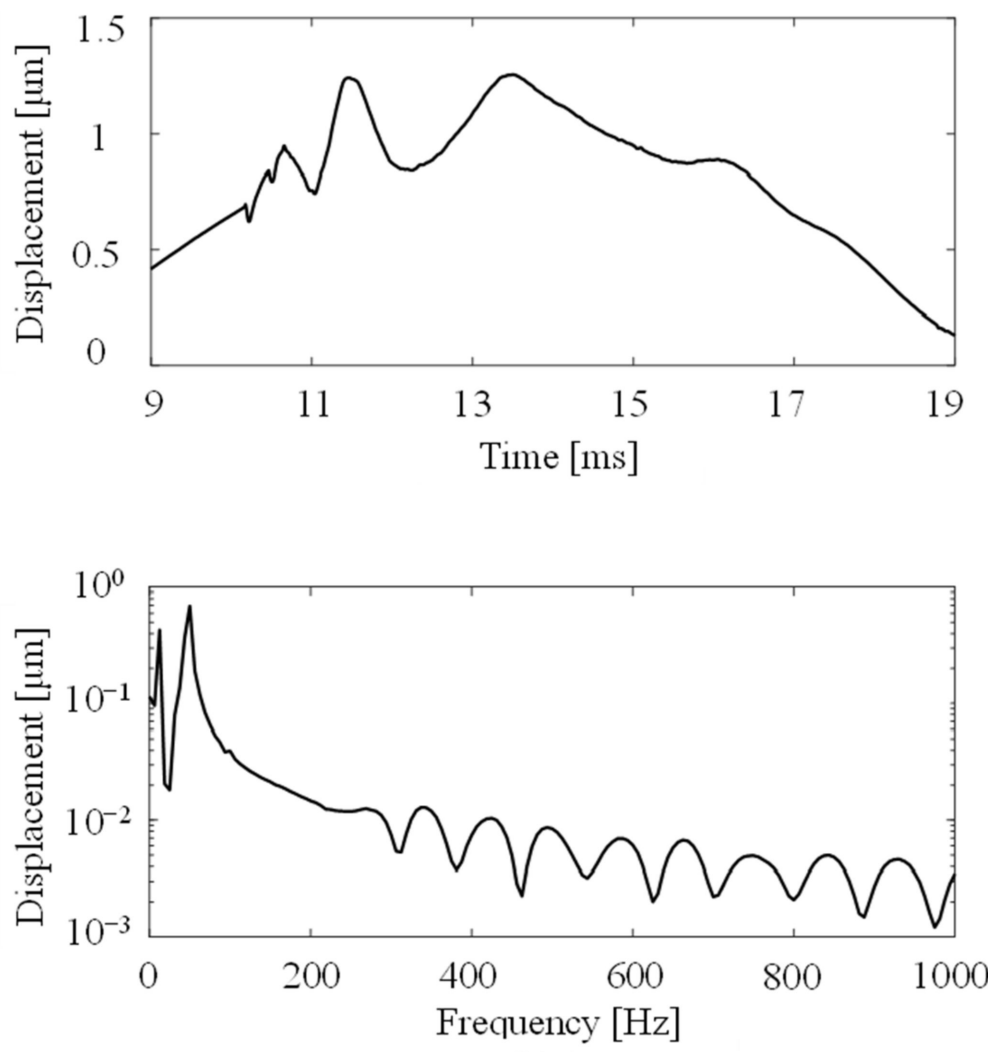

(b)
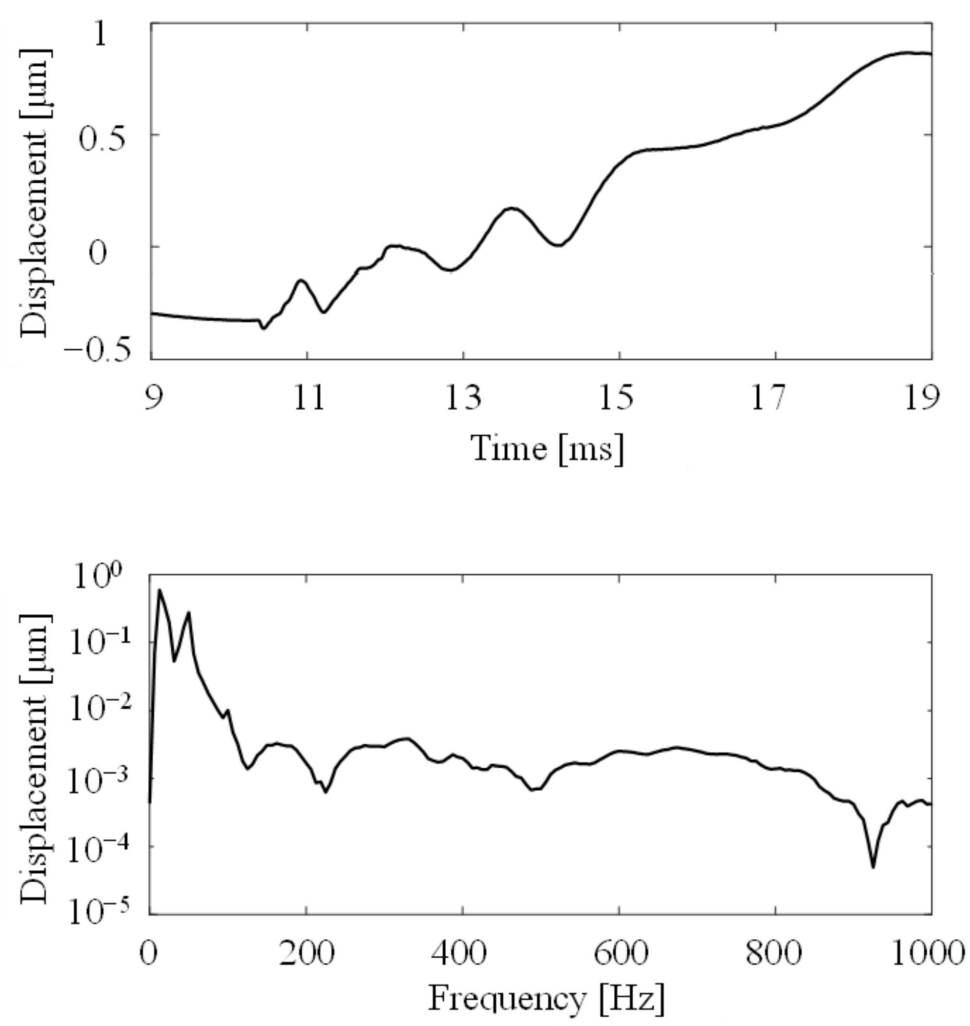

(c)

Figure 3. Time history responses and Fourier spectra of the measured displacement on mango 6 at (a) point 1, (b) point 12, and (c) point 24. (Measurement path: Line A). 


\subsection{Detection of the Rayleigh Wave Propagation Velocity}

We calculated the Rayleigh wave propagation velocity generated by our system. To show how the Rayleigh wave propagates, Figure 4 plots the time history responses of the measured displacement at points 1-24 on the mango peel arranged in order of the measurement points. The horizontal line shows the time, while the vertical line shows measurement points, and the color describes the amplitude of the Rayleigh wave. The slope of a line is the Rayleigh wave propagation velocity, which was calculated by the least-squares method.

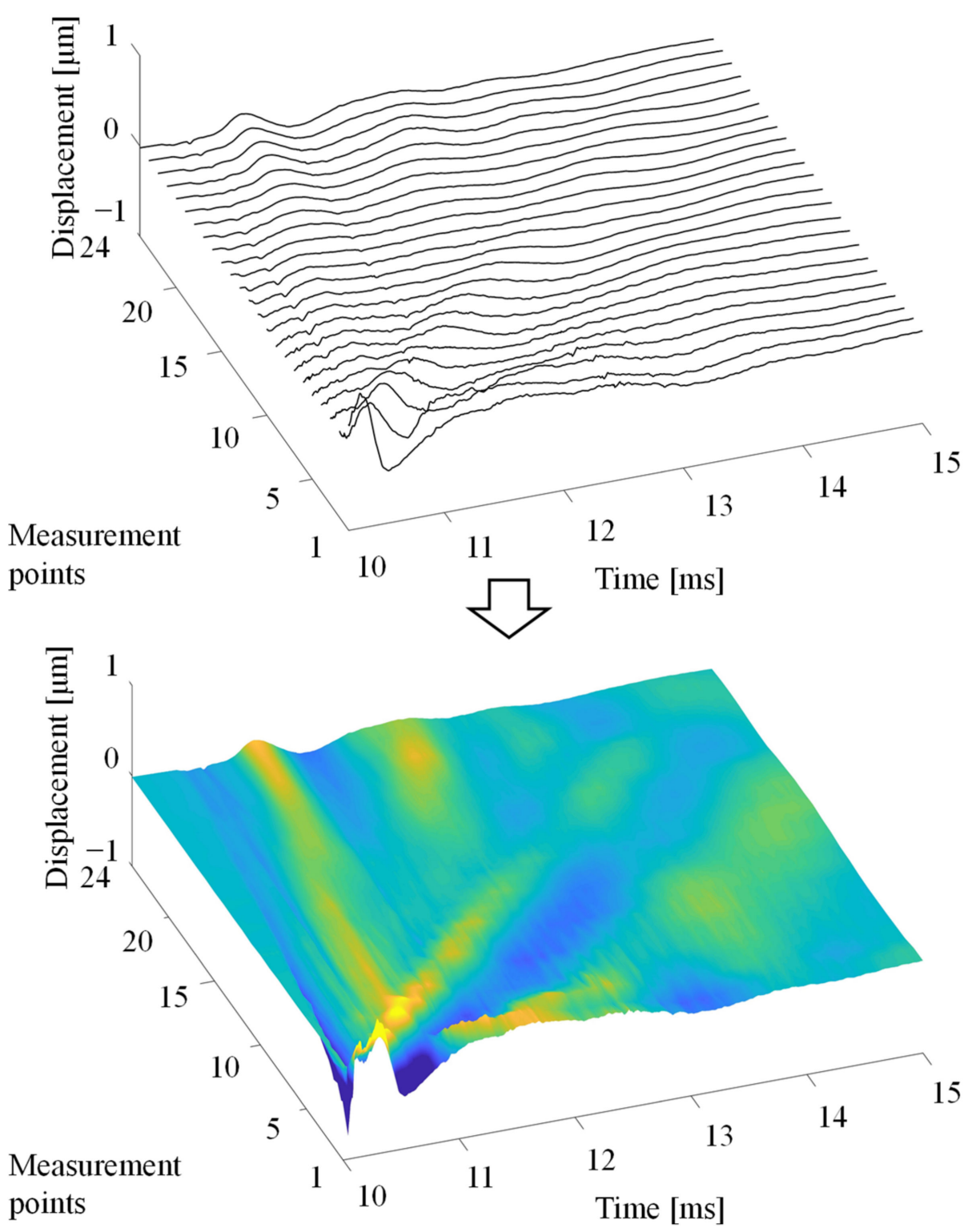

Figure 4. Visualization of Rayleigh wave propagation by arranging the time history responses of the measured displacement.

Figure 5 shows the Rayleigh wave propagation on mango 6 (Line A, $0 \mathrm{~h}$ ). The line had two slopes, which were calculated as 330 and $37 \mathrm{~m} / \mathrm{s}$. Therefore, one LIP shock wave propagated on the mango peel, while the other was the Rayleigh wave generated on the mangoes. 


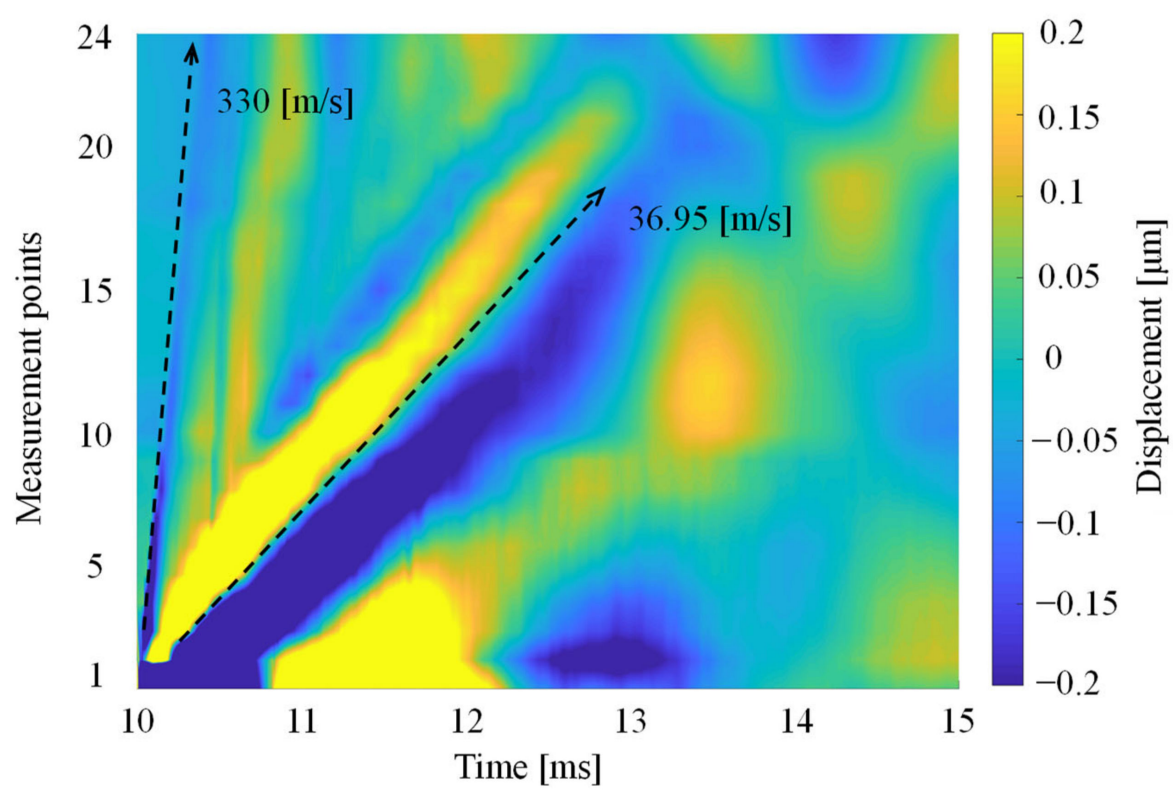

(a)

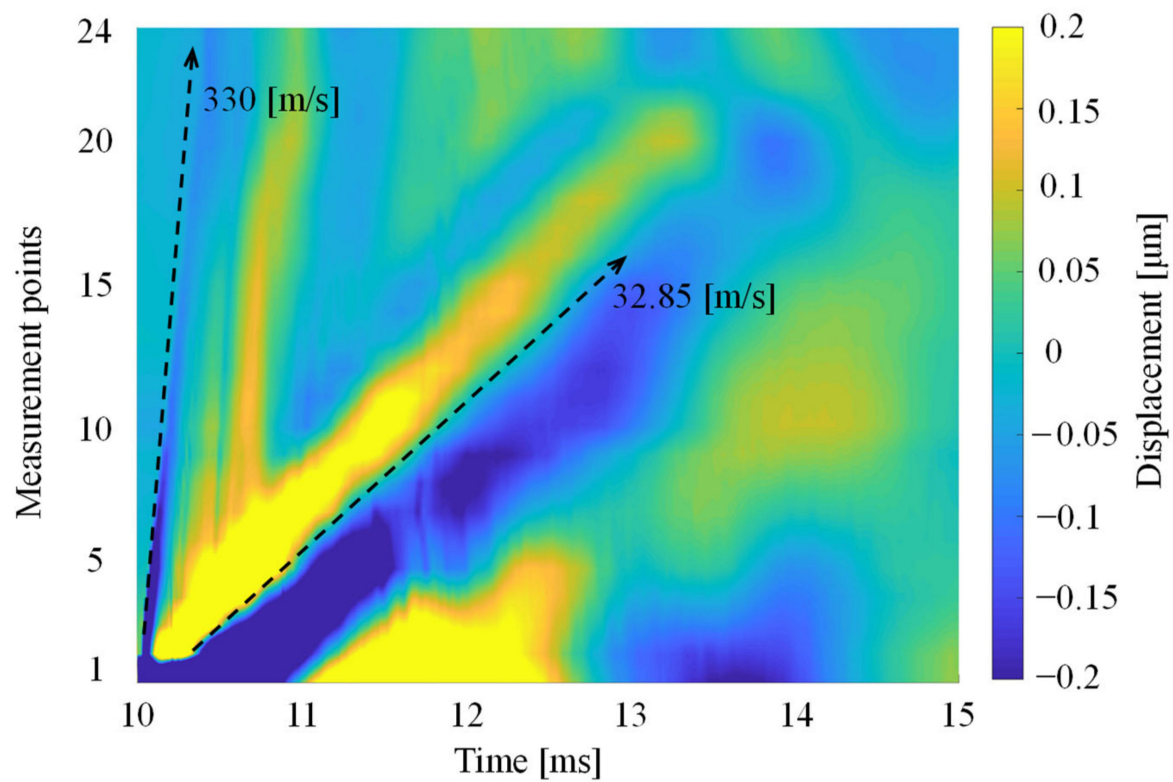

(b)

Figure 5. Rayleigh wave propagation on mango 6 on (a) Line A at 0 and (b) $216 \mathrm{~h}$.

\subsection{Shift in the Rayleigh Wave Velocity of Mangoes during Storage}

The Rayleigh wave propagation velocity $V[\mathrm{~m} / \mathrm{s}]$ is given by:

$$
V=\frac{0.87 \sigma+1.12 \sigma}{1+\sigma} \sqrt{\frac{G}{\rho}}
$$

where $G(\mathrm{~Pa}), \sigma$, and $\rho\left(\mathrm{kg} / \mathrm{m}^{3}\right)$ are the shear elasticity, Poisson's ratio, and density, respectively. The changes in $V$ can be regarded as the changes in $G$ if the changes in the density and Poisson's ratio of mangoes are sufficiently small that they can be ignored during the storage period. According to [52], shear elasticity of fruit flesh is strongly correlated to firmness. Here, we consider the change in the firmness of mangoes as the change in the Rayleigh wave propagation velocity. 
Figure 6 shows the relationship between the Rayleigh wave propagation velocity and the storage time of mango 6 at Line A (Figure 2). The Rayleigh wave propagation velocity decreased during storage. The reduction rates of the Rayleigh wave propagation velocity after 96 and $216 \mathrm{~h}$ were approximately $10 \%$ and $1.2 \%$, respectively. Therefore, we assumed that the changes in the firmness of mango 6 were nearly complete after $96 \mathrm{~h}$ of storage. Comparing the Rayleigh wave propagation velocities at 96 and $168 \mathrm{~h}$ revealed that the velocity increased by around 3\% although the storage time increased. The increased velocity is attributed to the error related to installation of the LDV and the measurement points. Since we put reflection seals (approximately $3 \mathrm{~mm} \times 3 \mathrm{~mm}$ ) at each measurement point, the average circumference $(270 \mathrm{~mm})$ contained approximately $\pm 6 \mathrm{~mm}$ error, indicating that the Rayleigh wave propagation velocity contained an approximately $\pm 4 \%$ measurement error. In this experiment, mangoes with a change rate in the Rayleigh wave velocity within $\pm 4 \%$ were not considered to have a change in the firmness as the threshold in the Rayleigh wave propagation velocity was $\pm 4 \%$.

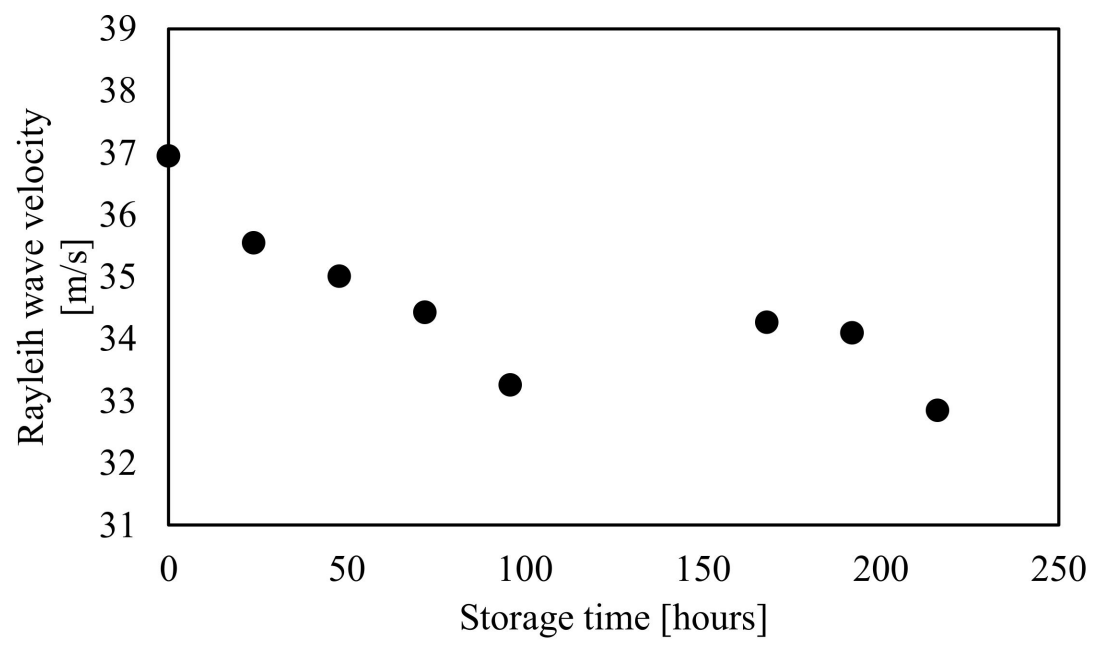

Figure 6. Relationship between the Rayleigh wave velocity and storage time of mango 6 (Measurement path: Line A).

Figure 7 shows the Rayleigh wave propagation velocity on mangoes 1-20 measured around Line A at 0,48 , and $96 \mathrm{~h}$. In addition, Figure 8 plots the change rate of the Rayleigh wave propagation velocity from 0 to $96 \mathrm{~h}$, where the $\pm 4 \%$ threshold is added as a reference. Almost all mangoes showed the same trend, where the Rayleigh wave propagation velocity decreased every $48 \mathrm{~h}$ (Figure 7). Although mangoes 1 and 14 slightly increased their Rayleigh wave propagation velocities, these were attributed to measurement error because the reduction rates of the Rayleigh wave propagation velocity for both mangoes were within the threshold (Figure 8). The Rayleigh wave propagation velocity increased by over $10 \%$ in $96 \mathrm{~h}$ for mangoes 16 and 18. Figure 9 shows cross-sectional pictures of mango 16, which were taken after the experiment. Mango 16 contained a cavity and showed some decay. Therefore, it is assumed that the Rayleigh wave propagation velocities of mangoes 16 and 18 increased due to the existence of the cavity near the measurement point or potential internal decay. 


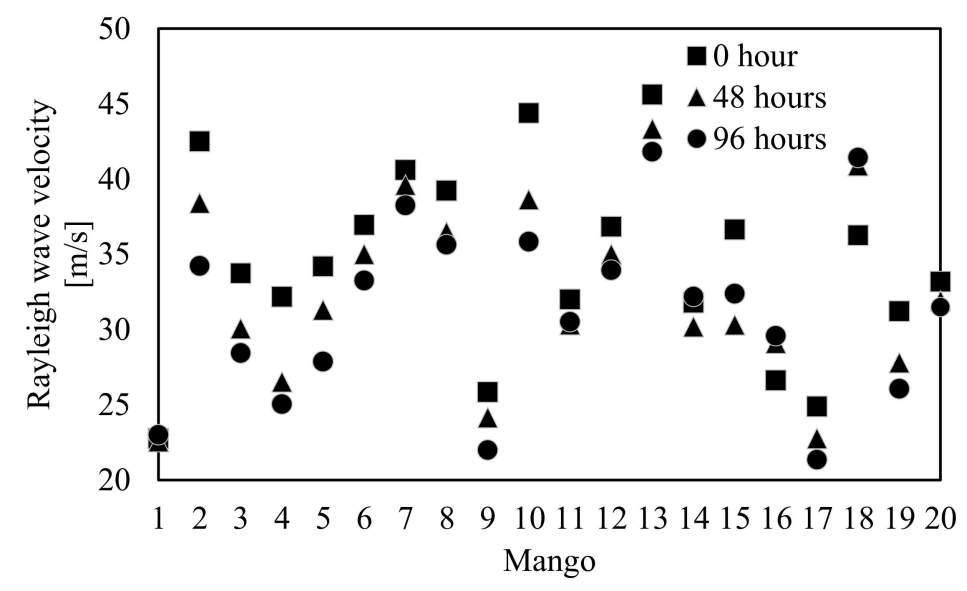

Figure 7. Shift in the Rayleigh wave velocity measured around Line A for mangoes 1-20 at 0, 48, and $96 \mathrm{~h}$.

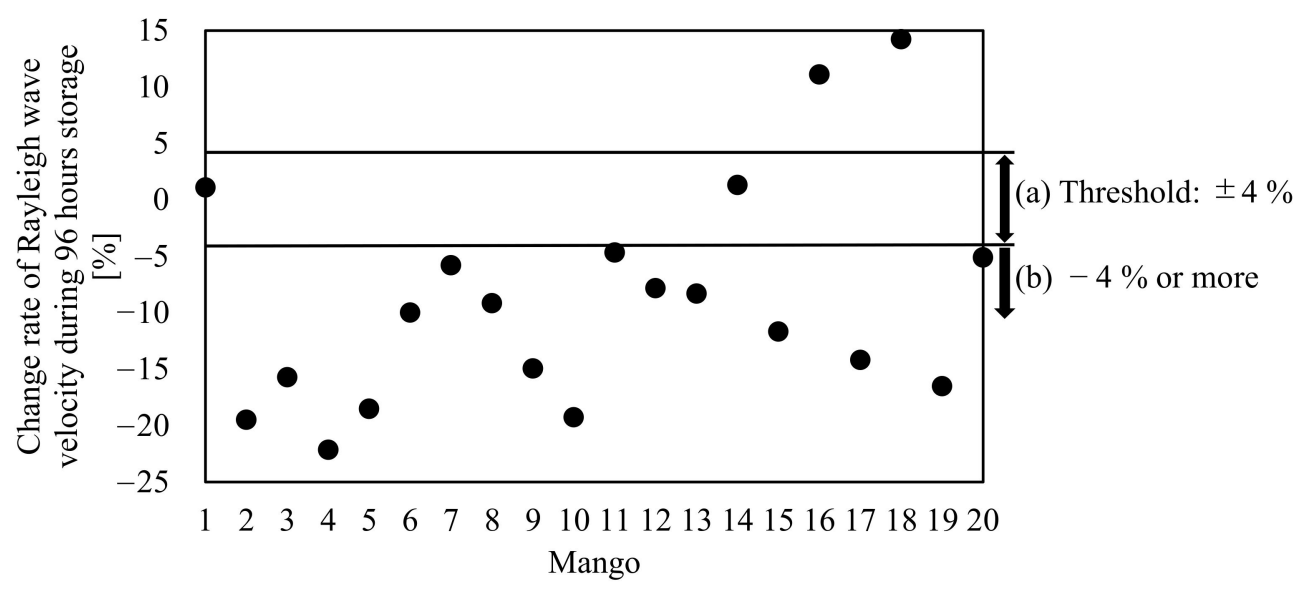

Figure 8. Change rate of the Rayleigh wave velocity measured around Line A of mangoes 1-20 after $96 \mathrm{~h}$ of storage. (a) Change rate of the Rayleigh wave is within the threshold. (b) Change rate of the Rayleigh wave exceeds the threshold.

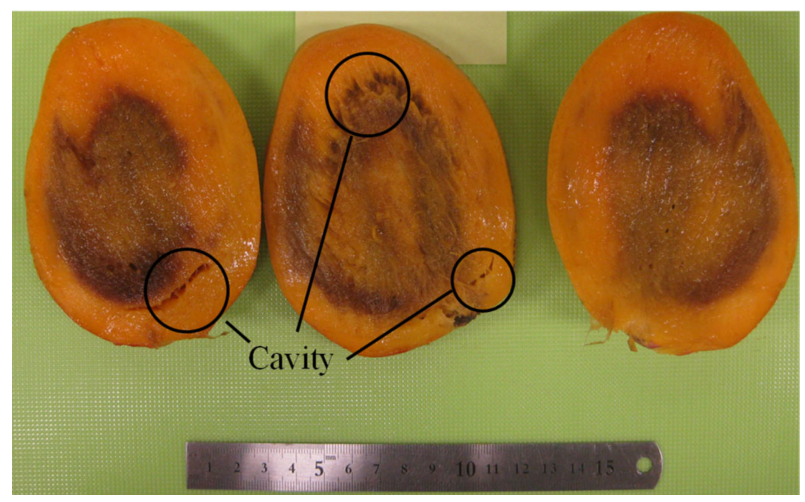

Figure 9. Cross-section picture that shows cavity decay (mango 16).

\subsection{Effect of a Seed on Measuring the Rayleigh Wave Propagation Velocity}

We investigated the effect of a seed on the measurement of the Rayleigh wave propagation velocity to consider the reliability of our method. The Rayleigh wave velocities that propagated on Lines A and B (Figure 2b) of mangoes 9-20 were measured. Figure 10 shows the Rayleigh wave propagations on Lines A and B of mango 12 at $0 \mathrm{~h}$. The Rayleigh wave propagated to point 24 on Line A, although it only propagated up to point 10 on Line B (Figure 10). Furthermore, the Rayleigh wave propagation velocities on Lines A and B were calculated as 36.8 and $41.6 \mathrm{~m} / \mathrm{s}$, respectively. 


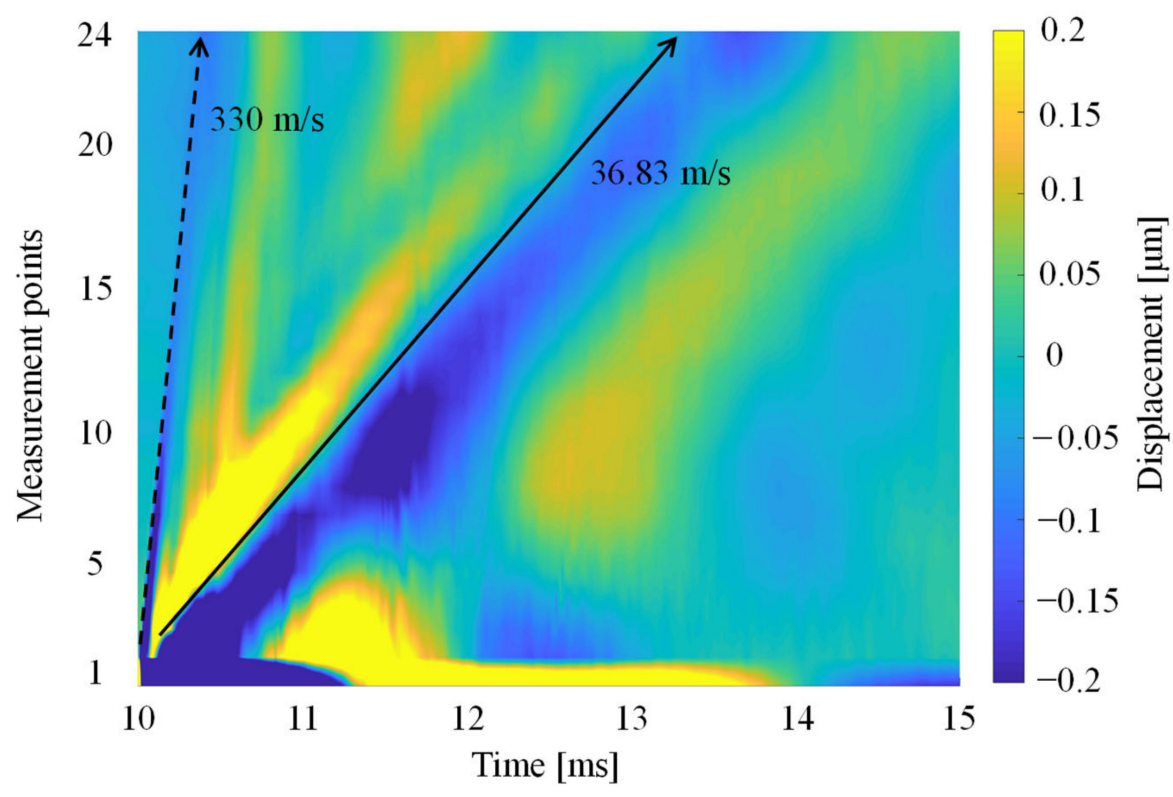

(a)

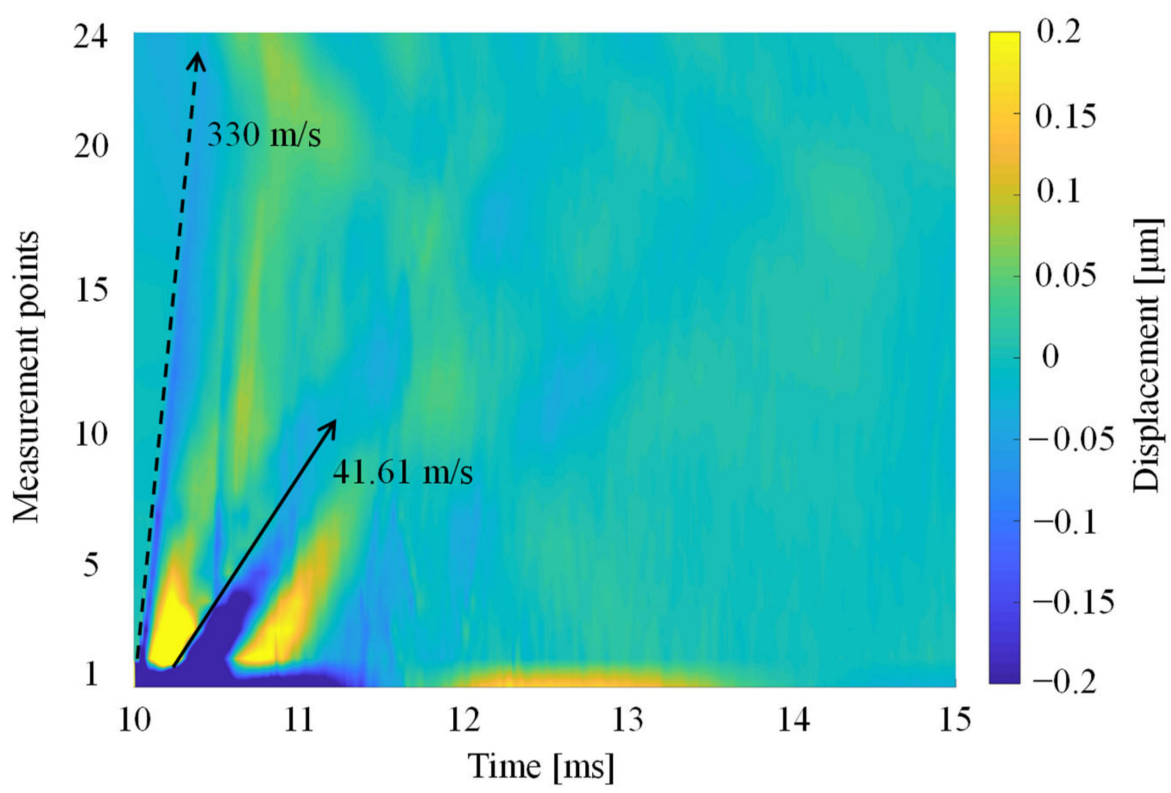

(b)

Figure 10. Rayleigh wave propagation on mango 12 at $0 \mathrm{~h}$. (a) Line A where the measurement points are on the equator, (b) Line B where the measurement points are orthogonal to the equator.

Figure 11 shows the Rayleigh wave propagation velocities on Lines A and B of mangoes 9-20 at $0 \mathrm{~h}$. The propagation velocities on Line B were larger than those on Line A, except for mangoes 10 and 18. The propagation velocities of mangoes 10 and 18 on Line $\mathrm{B}$ were smaller than those on Line A, which can be explained by the measurement error because they are within the $4 \%$ threshold. A previous study found that the Rayleigh wave propagation velocity depended on the fruit flesh thickness [52]. Therefore, the mango seed might have affected the propagation velocity on Line B. 


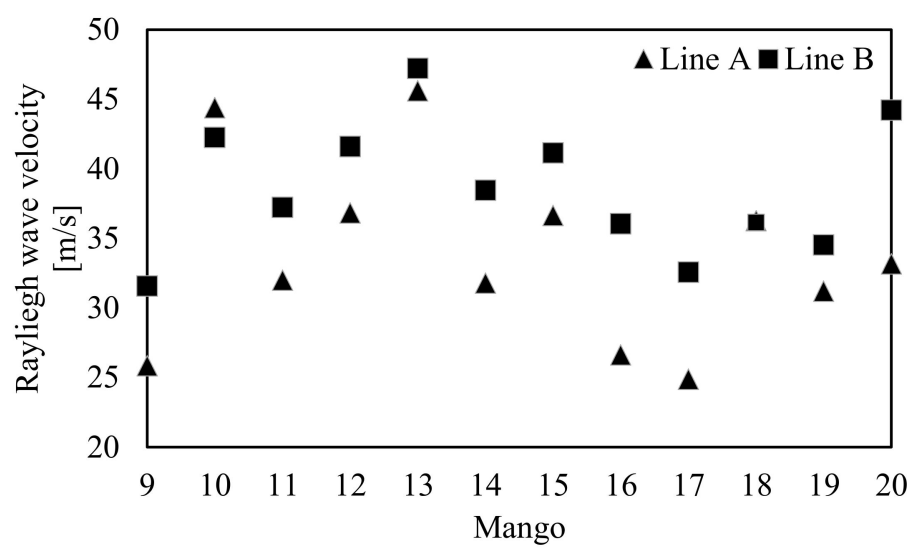

Figure 11. Rayleigh wave velocity measured around Line A and Line B of mangoes 9-20 at $0 \mathrm{~h}$.

Next, Figure 12 shows the change rate of the Rayleigh wave propagation velocities of mangoes 9-20 on Lines A and B. In Figure 12, the change rate of the propagation velocity was calculated using 0 and $96 \mathrm{~h}$. The Rayleigh wave propagation velocities on Lines A and $B$ showed the same trend, where the velocity decreased during storage. We could not detect a shift in the firmness of mangoes 12 and 15 on Line B because their change rates of the Rayleigh wave propagation velocity were within the $4 \%$ threshold. Nevertheless, the shifts in firmness of mangoes 12 and 15 were detected based on Line A. Mangoes 16 and 18 increased their propagation velocities on Lines A and B during storage, indicating that they might have had a cavity near the measurement point or potential decay inside. These results imply that the Rayleigh wave along Line A is less susceptible to seed-related effects and is better suited for the firmness assessment than Line B. In the future, we will investigate the locations of the measurement area for firmness assessment of mangoes in detail.

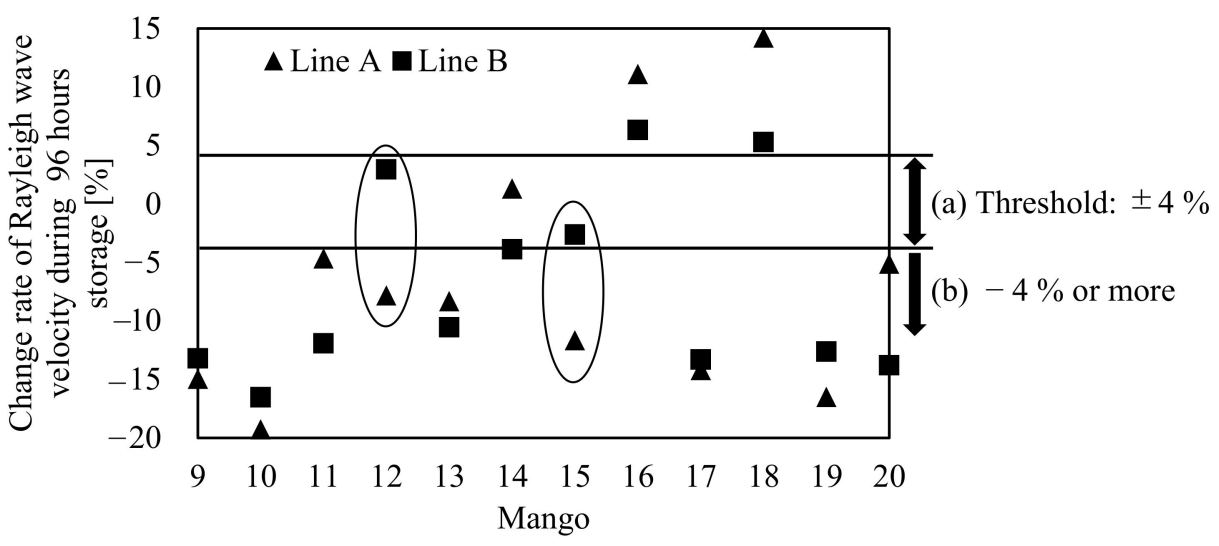

Figure 12. Change rate of Rayleigh wave velocity measured around Line A and Line B of mangoes 9-20 during 96-h storage. (a) Change rates of Rayleigh wave are within threshold. (b) Change rate of Rayleigh wave exceeds threshold.

\section{Conclusions}

This work realized a firmness assessment for soft-flesh mangoes using a LIP shock wave excitation technique. LIP is generated near the excitation point on mangoes by condensing a high-output Nd:YAG pulsed laser.

The experiment, which employed 20 Kent mangoes as test materials, confirmed that our system can generate a Rayleigh wave on a mango fruit by applying an impulse excitation force based on the LIP shock wave excitation technique. Next, Rayleigh waves were generated on the mangoes during storage and their propagation velocity was investigated. The Rayleigh wave propagation velocity decreased as the storage time increased. The 
Rayleigh wave propagation velocity on the equator of Kent mangoes tended to decrease by over $4 \%$ in $96 \mathrm{~h}$. The Rayleigh wave measured on two different lines propagated an independent distance and showed a different change rate of propagation velocity during 96-h storage.

The ${ }_{0} S_{2}$ mode frequency, which is traditionally used for flesh fruit firmness assessments, was not excited on the mangoes used in the experiment. These results demonstrate that our system is effective for non-contact and non-destructive firmness assessments for fruit such as mangoes, which do not show the ${ }_{0} S_{2}$ mode frequency.

We investigated the suitable measurement location for firmness assessment of mangoes. One was set on the equator, which is where the ${ }_{0} S_{2}$ mode frequency is traditionally measured in fruit firmness assessments. The other was set on the orthogonal direction to the equator. If the firmness is assessed on the orthogonal direction to the equator, a mango may estimate more firmly than an actual state. This is because the Rayleigh wave propagation velocity on the orthogonal to the equator was larger than that on the equator. The reduction rate of the Rayleigh wave propagation velocity on the equator during storage tended to be greater than that on the orthogonal line to the equator. Hence, the Rayleigh wave propagation velocity should be measured on the equator for the firmness assessment of mangoes. In the future, we will consider in detail the point where a Rayleigh wave is excited (excitation point) and the measurement area where the wave propagates.

Author Contributions: Conceptualization, N.H.; methodology, N.H.; software, N.A.; validation, N.H., N.A. and I.K.; formal analysis, N.A., M.M. and K.Y.; investigation, N.H. and N.A.; resources, N.A., M.M. and K.Y.; data curation, N.A. and N.H.; writing-original draft preparation, N.A. and N.H.; writing-review and editing, N.H., N.A. and I.K.; visualization, N.A.; supervision, N.H.; project administration, N.H.; funding acquisition, N.H. All authors have read and agreed to the published version of the manuscript.

Funding: This research was partly supported by the Tojuro Iijima Foundation for Food Science and Technology, grant number 25, and the Japan Society for the Promotion of Science for their support under Grants-in-Aid for Scientific Research Programs (Grants-in-Aid for Scientific Research (B), Project No. JP 19H02088).

Institutional Review Board Statement: Not applicable.

Informed Consent Statement: Not applicable.

Conflicts of Interest: The authors declare no conflict of interest. The funders had no role in the design of the study; in the collection, analyses, or interpretation of data; in the writing of the manuscript, or in the decision to publish the results.

\section{References}

1. Nordey, T.; Lechaudel, M.; Genard, M.; Joas, J. Factors affecting ethylene and carbon dioxide concentrations during ripening: Incidence on final dry matter, total soluble solids content and acidity of mango fruit. J. Plant Physiol. 2016, 196-197, 70-78. [CrossRef] [PubMed]

2. Guo, Z.; Huang, W.; Peng, Y.; Chen, Q.; Ouyang, Q.; Zhao, J. Color compensation and comparison of shortwave near infrared and long wave near infrared spectroscopy for determination of soluble solids content of 'Fuji' apple. Postharvest Biol. Technol. 2016, 115, 81-90. [CrossRef]

3. Fan, S.; Zhang, B.; Li, J.; Huang, W.; Wang, C. Effect of spectrum measurement position variation on the robustness of NRI spectroscopy models for soluble solids content of apple. Biosyst. Eng. 2016, 143, 9-19. [CrossRef]

4. Zude, M.; Herold, B.; Roger, J.; Bellon-Maurel, V.; Landahl, S. Non-destructive tests on the prediction of apple fruit flesh firmness and soluble solids content on tree and in shelf life. J. Food Eng. 2006, 77, 254-260. [CrossRef]

5. Peng, Y.; Lu, R. Prediction of apple fruit firmness and soluble solids content using characteristics of multispectral scattering images. J. Food Eng. 2007, 82, 142-152. [CrossRef]

6. Kawano, S.; Watanabe, H.; Iwamoto, M. Determination of sugar content in intact peaches by near infrared spectroscopy with fiber optics in interactance mode. J. Jpn. Soc. Hort. Sci. 1992, 61, 445-451. [CrossRef]

7. Ma, T.; Li, X.; Inagaki, T.; Yang, H.; Tsuchikawa, S. Noncontact evaluations of soluble solids content in apples by near-infrared hyperspectral imaging. J. Food Eng. 2018, 224, 53-61. [CrossRef]

8. Perez-Marin, D.; Sanchez, M.; Paz, P.; Soriano, M.; Guerrero, J.; Garrido-Varo, A. Non-destructive determination of quality parameters in nectarines during on-tree ripening and postharvest storage. Postharvest Biol. Technol. 2009, 52, 180-188. [CrossRef] 
9. Mendoza, F.; Lu, R.; Ariana, D.; Cen, H.; Bailey, B. Integrated spectral and image analysis of hyperspectral scattering data for prediction of apple fruit firmness and soluble solids content. Postharvest Biol. Technol. 2011, 62, 149-160. [CrossRef]

10. Munera, S.; Amigo, J.M.; Blasco, J.; Cubero, S.; Talens, P.; Aleixos, N. Ripeness monitoring of two cultivars of nectarine using VIS-NIR hyperspectral reflectance imaging. J. Food Eng. 2017, 214, 29-39. [CrossRef]

11. Rungpichayapichet, P.; Mahayothee, B.; Nagle, M.; Khuwijitjaru, P.; Muller, J. Robust NIRS models for non-destructive prediction of postharvest fruit ripeness and quality in mango. Postharvest Biol. Technol. 2016, 111, 31-40. [CrossRef]

12. Minas, I.S.; Blanco-Cipollone, F.; Sterle, D. Accurate non-destructive prediction of peach fruit internal quality and physiological maturity with a single scan using near infrared spectroscopy. Food Chem. 2021, 335, 127626. [CrossRef] [PubMed]

13. Ventura, M.; Jager, A.; Putter, H.; Roelofs, F.P.M.M. Non-destructive determination of soluble solids in apple fruit by near infrared spectroscopy (NIRS). Postharvest Biol. Technol. 1998, 14, 21-27. [CrossRef]

14. Schmilovitch, Z.; Mizrach, A.; Hoffman, A.; Egozi, H.; Fuchs, Y. Determination of mango physiological indices by near-infrared spectrometry. Postharvest Biol. Technol. 2000, 19, 245-252. [CrossRef]

15. Saranwong, S.; Sornsrivichai, J.; Kawano, S. Prediction of ripe-stage eating quality of mango fruit from its harvest quality measured nondestructively by near infrared spectroscopy. Postharvest Biol. Technol. 2004, 31, 137-145. [CrossRef]

16. Liu, H.; An, K.; Su, S.; Yu, Y.; Wu, J.; Xiao, G.; Xu, Y. Aromatic characterization of mangoes (Mangifera indica L.) using solid phase extraction coupled with gas chromatography-mass spectrometry and olfactometry and sensory analysis. Foods. 2020, 9, 75. [CrossRef]

17. Fernandez-Trujillo, J.P.; Dos-Santos, N.; Martinez-Alcaraz, R.; Bleis, I.L. Non-destructive assessment of aroma volatiles from a climacteric near-isogenic line of melon obtained by headspace stir-bar sorptive extraction. Foods. 2013, 2, 401-414. [CrossRef]

18. Wei, Z.; Wang, J.; Zhang, W. Detecting internal quality of peanuts during storage using electronic nose responses combined with physicochemical methods. Food Chem. 2015, 177, 89-96. [CrossRef]

19. Lebrun, M.; Plotto, A.; Goodner, K.; Ducamp, M.; Baldwin, E. Discrimination of mango fruit maturity by volatiles using the electric nose and gas chromatography. Postharvest Biol. Technol. 2008, 48, 122-131. [CrossRef]

20. Kendra, P.E.; Roda, A.L.; Montgomery, W.S.; Schnell, E.Q.; Niogret, J.; Epsky, N.D.; Heath, R.R. Gas chromatography for detection of citrus infestation by fruit fly larvae (Diptera: Tephritidae). Postharvest Biol. Technol. 2011, 59, 143-149. [CrossRef]

21. Zhang, B.; Xi, W.; Wei, W.; Shen, J.; Ferguson, I.; Chen, K. Changes in aroma-related volatiles and gene expression during low temperature storage and subsequent shelf-life of peach fruit. Postharvest Biol. Technol. 2011, 60, 7-16. [CrossRef]

22. Landahl, S.; Terry, L.A. Non-destructive discrimination of avocado fruit ripeness using laser Doppler vibrometry. Biosyst. Eng. 2020, 194, 251-260. [CrossRef]

23. Fathizadeh, Z.; Aboonajmi, M.; Beygi, S.R.H. Nondestructive firmness prediction of apple fruit using acoustic vibration response. Sci. Hortic. 2020, 262, 109073. [CrossRef]

24. Kim, K.; Lee, S.; Kim, M.; Cho, B. Determinatino of apple firmness by nondestructive ultrasonic measurement. Postharvest Biol. Technol. 2009, 52, 44-48. [CrossRef]

25. Vasighi-Shojae, H.; Gholami-Parashkouhi, M.; Mohammadzamani, D.; Soheili, A. Ultrasonic based determination of apple quality as a nondestructive technology. Sens. Bio-Sens. Res. 2018, 21, 22-26. [CrossRef]

26. Baltazar, A.; Aranda, J.I.; Gonzalez-Aguilar, G. Bayesian classification of ripening stages of tomato fruit using acoustic impact and colorimeter sensor data. Comput. Electron. Agric. 2008, 60, 113-121. [CrossRef]

27. Schotte, S.; Belie, N.D.; Baerdemaeker, J.D. Acoustic impulse-response technique for evaluation and modelling of firmness of tomato fruit. Postharvest Biol. Technol. 1999, 17, 105-115. [CrossRef]

28. Shmulevich, I.; Galili, N.; Howarth, M.S. Nondestructive dynamic testing of apples for firmness evaluation. Postharvest Biol. Technol. 2003, 29, 287-299. [CrossRef]

29. Gomez, A.H.; Wang, J.; Pereira, A.G. Impulse response of pear fruit and its relation to Magness-Taylor firmness during storage. Postharvest Biol. Technol. 2005, 35, 209-215. [CrossRef]

30. Ketelaere, B.D.; Howarth, M.S.; Crezee, L.; Lammertyn, J.; Viaene, K.; Bulens, I.; Baerdemaeker, J.D. Postharvest firmness changes as measured by acoustic and low-mass impact devices: A comparison of techniques. Postharvest Biol. Technol. 2006, 41, 275-284.

31. Duprat, F.; Grotte, M.; Pietri, E.; Loonis, D. The Acoustic Impulse Response Method for Measuring the Overall Firmness of Fruit. J. Agric. Eng. Res. 1997, 66, 251-259. [CrossRef]

32. Cooke, J.R. An Interpretation of the Resonant Behavior of Intact Fruits and Vegetables. ASABE 1972, 15, 1075-1080. [CrossRef]

33. Hosoya, N.; Mishima, M.; Kajiwara, I.; Maeda, S. Non-destructive firmness assessment of apples using a non-contact laser excitation system based on a laser-induced plasma shock wave. Postharvest Biol. Technol. 2017, 128, 11-17. [CrossRef]

34. Kajiwara, I.; Akita, R.; Hosoya, N. Damage detection in pipes based on acoustic excitations using laser-induced plasma. Mech. Syst. Sig. Process. 2018, 111, 570-579. [CrossRef]

35. Hosoya, N.; Yoshinaga, A.; Kanda, A.; Kajiwara, I. Non-contact and non-destructive Lamb wave generation using laser-induced plasma shock wave. Int. J. Mech. Sci. 2018, 140, 486-492. [CrossRef]

36. Huda, F.; Kajiwara, I.; Hosoya, N. Damage detection in membrane structures using non-contact laser excitation and wavelet transformation. J. Sound Vib. 2014, 333, 3609-3624. [CrossRef]

37. Hosoya, N.; Nagata, M.; Kajiwara, I. Acoustic testing in a very small space based on a point sound source generated by laser-induced breakdown: Stabilization of plasma formation. J. Sound Vib. 2013, 332, 4572-4583. [CrossRef] 
38. Hosoya, N.; Kajiwara, I.; Inoue, T.; Umenai, K. Non-contact acoustic tests based on nanosecond laser ablation: Generation of a pulse sound source with a small amplitude. J. Sound Vib. 2014, 333, 4254-4264. [CrossRef]

39. Hosoya, N.; Kajiwara, I.; Umenai, K.; Maeda, S. Dynamic characterizations of underwater structures using noncontact vibration tests based on nanosecond laser ablation in water: Evaluation of passive vibration suppression with damping materials. J. Vib. Control. 2018, 24, 3714-3725. [CrossRef]

40. Huda, F.; Kajiwara, I.; Hosoya, N.; Kawamura, S. Bolt loosening analysis and diagnosis by non-contact laser excitation vibration tests. Mech. Syst. Sig. Process. 2013, 40, 589-604. [CrossRef]

41. Kurahashi, S.; Mikami, K.; Kitamura, T.; Hasegawa, N.; Okada, H.; Kondo, S.; Nishikino, M.; Kawachi, T.; Shimada, Y. Demonstration of 25-Hz-inspection speed laser remote sensing for internal concrete defects. J. Appl. Remote Sens. 2018, $12,015009$. [CrossRef]

42. Hosoya, N.; Umino, R.; Kanda, A.; Kajiwara, I.; Yoshinaga, A. Lamb wave generation using nanosecond laser ablation to detect damage. J. Vib. Control. 2018, 24, 5842-5853. [CrossRef]

43. Hosoya, N.; Terashima, Y.; Umenai, K.; Maeda, S. High spatial and temporal resolution measurement of mechanical properties in hydrogels by non-contact laser excitation. AIP Adv. 2016, 6, 095223.

44. Hitchman, S.; Wijk, K.; Davidson, Z. Monitoring attenuation and the elastic properties of an apple with laser ultrasound. Postharvest Biol. Technol. 2016, 121, 71-77. [CrossRef]

45. Podymova, N.B.; Kalashnikov, I.E.; Bolotova, L.K.; Kobeleva, L.I. Laser-ultrasonic nondestructive evaluation of proposity in particulate reinforced metal-matrix composites. Ultrasonics 2019, 99, 105959. [CrossRef] [PubMed]

46. Ji, B.; Zhang, Q.; Cao, J.; Li, H.; Zhang, B. Non-contact detection of delamination in stainless steel/carbon steel composites with laser ultrasonic. Optik 2021, 26, 165893. [CrossRef]

47. Cao-Rial, M.T.; Moreno, C.; Quintela, P. Determination of Young modulus by using Rayleigh waves. Appl. Math. Modell. 2020, 77, 439-455. [CrossRef]

48. Yue, Z.; Qiu, P.; Yang, R.; Yang, G. Experimental study on a Mach cone and trailing Rayleigh waves in a stress wave chasing running crack problem. Theor. Appl. Fract. Mech. 2019, 104, 102371. [CrossRef]

49. Na, J.K.; Blackshire, J.L. Interaction of Rayleigh surface waves with a tightly closed fatigue crack. NDTEE Int. 2010, 43, 432-439.

50. Pfeifer, D.; Kim, J.; Jacobs, L.J. Nonlinear Rayleigh waves to evaluate plasticity damage in X52 pipeline material. Mech. Syst. Sig. Process. 2020, 143, 106794. [CrossRef]

51. Onodera, Y.; Choi, P.-K. Surface-wave models on soft gels. J. Acoust. Soc. Am. 1998, 104, 3358-3363. [CrossRef]

52. Ikeda, T.; Choi, P.K.; Ishii, T.; Arai, I.; Osawa, M. Firmness evaluation of watermelon flesh by using surface elastic waves. J. Food Eng. 2015, 160, 28-33. [CrossRef]

53. Hosoya, N.; Nagata, M.; Kajiwara, I.; Umino, R. Nano-second Laser induced Plasma shock wave in Air for non-contact Vibration Tests. Exp. Mech. 2016, 56, 1305-1311. [CrossRef]

54. Georgiev, V.B.; Krylov, V.V.; Qin, Q.; Attenborough, K. Generation of flexural waves in plates by laser- initiated airborne shock waves. J. Sound Vib. 2011, 330, 217-228. [CrossRef] 